\title{
The quantitative genetics of floral characters in Mimulus guttatus
}

\author{
ALASTAIR W. ROBERTSON*, ANITA DIAZ \& MARK R. MACNAIR \\ Department of Biological Sciences, University of Exeter, Exeter EX4 4PS, U.K.
}

\begin{abstract}
We examined the quantitative genetics of 20 floral traits in Mimulus guttatus including flowering time, autofertility, flower size, the spatial arrangement of flower parts, pollen and ovule production and seed number and size. A six by six diallel crossing design including selfs was performed in the glasshouse between plants derived from one population of $M$. guttatus from California. All characters with the exception of pollen number showed significant amounts of additive genetic variance indicating a potential to respond to selection. A principal components analysis revealed that some variation in many characters could be explained by general flower size. However, most characters still displayed heritable variation after the flower size effect was removed by analysis of covariance. Families showed considerable variation in the ability to self in glasshouse conditions. Only a weak relationship between autofertility and herkogamy was detected, suggesting that an unidentified mechanism was responsible for differences in selfing ability. Pollen quality and ovule production were also strongly heritable, suggesting the potential for gender specialization of plants but no trade-off between male and female function could be detected. Inbreeding depression was evident in flower size and pollen and ovule production. It is postulated that the heritable variation observed is maintained in this population through disruptive selection on autofertility in response to seasonal variation in the onset of spring drought and pollinator availability.
\end{abstract}

Keywords: additive genetic variances, autofertility, floral traits, male-female trade-offs, Mimulus guttatus, sex allocation.

\section{Introduction}

Much of the effort of over a century of investigations in floral biology has been devoted to studying the process of the coevolution of flowers and their pollinators (Darwin, 1862; Baker, 1983). Recently, investigations have begun to confirm that intrapopulation differences in microfloral characters of the size and spatial relationships of floral parts are often reflected in differential plant fitness (Galen, 1989; Campbell, 1991; Campbell et al., 1991; Stanton et al., 1991). Such selective differentials may drive floral evolution and continue the process of plant-pollinator co-evolution. However, in order for selection to respond to such differences in fitness, the variance among parents must be at least partially heritable to allow for changes to occur in the average phenotype of the resulting offspring. Despite its clear importance, the additive

${ }^{*}$ Correspondence: Ecology Department, School of Biological Sciences, Massey University, Private Bag 11222, Palmerston North, New Zealand. genetic variance of floral traits of wild plants has rarely been examined (Mitchell-Olds \& Rutledge, 1986).

Theory predicts that characters closely associated with fitness will have low additive genetic variance as directional selection will have exhausted any additive component (Fisher, 1930; Falconer, 1989). However, others have argued that various circumstances may maintain heritable variation in these traits by a mutation-selection balance (Lande, 1976), by antagonistic pleiotropy leading to genetic trade-offs (Rose, 1982; Falconer, 1989) or by selection varying in time and space (Haldane \& Jayakar, 1963). The few studies of fitness traits of plants that have been published show that while some characters display moderate heritable variation, many have little or no detectable additive component (Arthur et al., 1973, and references therein; Mitchell-Olds, 1986; Mazer, 1987; Biere, 1991a,b; Dorn \& Mitchell-Olds, 1991; Schwaegerle \& Levin, 1991). It is not clear, therefore, whether observed phenotypic variation in plant traits generally has a heritable basis that may respond to natural selection. Here, we present a quantitative genetic analysis of the heritability of floral traits of Mimulus guttatus. 
M. guttatus is a weedy hermaphrodite perennial native to the western part of the United States and is becoming an increasingly important model for the study of plant evolution (Ritland \& Ganders, 1987a, b; Macnair and Cumbes, 1989; Ritland, 1989; Dole, 1990, 1992; Searcy \& Macnair, 1990; Dudash \& Ritland, 1991). Many characters vary phenotypically both between and within populations. Crosses between species within the $M$. guttatus complex reveal that at the interspecific level, variation in many floral characters is heritable (Macnair \& Cumbes, 1989). Another study has revealed significant within-population, broad-sense heritabilities for pollen, ovule and seed production in material of $M$. guttatus grown from seed from the same site as used for the present study (Mossop et al., 1994). There are no published estimates of additive genetic variation in floral traits within populations of $M$. guttatus, however.

In addition to selective pressures imposed by animal pollinators, floral form may be directed by the evolution of autogamy. Increasing selfing has often been shown to involve changes in the spatial arrangement of flowers, particularly a reduction of the stigmaanther separation (herkogamy) (Vasek, 1965; Rick et al., 1977; Robertson \& Lloyd, 1991). M. guttatus shows intermediate levels of selfing in its native habitat (Ritland \& Ganders, 1987a). Other work has indicated that self-pollination in this species may be associated with either reduced herkogamy or late-acting selfing during corolla abscission (Dole, 1990, 1992). This study tests the functional relationship between herkogamy and autofertility in glasshouse-grown plants of $M$. guttatus.

Trade-offs between functions may further constrain the evolution of quantitative characters (Rose, 1982). Hermaphrodite flowers have two components of fitness - that of the male through pollen and the female through seeds. An increase in allocation to the male function, for instance, must produce an increase in male fitness that exceeds any loss incurred in the female function and vice versa. Here, we examine evidence for a trade-off between pollen and ovule production.

This paper attempts the following: (i) to determine the amount of additive genetic variance of several floral characters including pollen and ovule production and autofertility; (ii) to look for functional relationships between autofertility and the other measured characters; and (iii) to look for evidence for a trade-off between pollen and ovule production.

\section{Materials and methods}

\section{Origin and rearing of $\mathrm{M}$. guttatus}

The parent plants of $M$. guttatus used in this study were chosen from a group of plants grown in a glasshouse in Exeter from seeds collected at Copperopolis mine in Calveras County, CA $\left(37^{\circ} 58^{\prime} \mathrm{N}, 120^{\circ} 38^{\prime}\right.$ W). Initially, the objectives of the study were to study the genetic nature of observed variation in pollen viability, so six genotypes were chosen from an initial group of approximately 60 plants, to encompass the range of pollen viability present.

A cutting was made of each genotype and allowed to flower in a glasshouse. Hand-pollinations were performed between all possible combinations including selfs in a complete and balanced $6 \times 6$ diallel design. Two flowers were pollinated for each combination to ensure at least one filled capsule was obtained. A small number of seeds from each cross was sown and after several days seedlings were pricked out into John Innes compost in $6.4 \mathrm{~cm}$ pots. Three were chosen at random and placed within a randomized block on a glasshouse bench that was isolated from potential insect pollinators. Occasional spraying with insecticide and fungicide prevented damage. Flowering was induced by long days (16 h) after 21 days. Two similar sets of plants were grown, separated by several weeks and placed in different glasshouses.

\section{Characters scored}

As the plants came into flower, the day to first flowering was recorded and 19 other characters were scored (Table 1, Fig. 1). All the floral traits were measured on flowers from the first two nodes of the main stem. All the metric characters were scored using a digital calliper capable of reading to $0.1 \mathrm{~mm}$.

One flower was removed and scored for pollen and ovule production. The size of the ovary was measured with a stereomicroscope. The ovary was assumed to be a cylinder and volume therefore calculated as volume $=$ ovary length $\pi(0.5 \text { ovary width })^{2}$.

A selection of these ovaries (representing contributions from all parents and including ovaries from block 1 that had been in flower for a fortnight; see below) was further measured to determine ovule number. One of the two locules was teased open into a drop of water on a microscope slide and all the ovules released. The whole slide was systematically scanned and the ovules counted. Ovule number and ovary size were found to be highly correlated (ovule number $=389.05$ (ovary volume $\left.\left.{ }^{0.635}\right), R^{2}=0.61, P<0.0001\right)$ and ovary size may therefore reliably be used as a predictor of ovule number. 
Table 1 Description of characters 1-19, character 20-loadings on the first component of a Principal Components Analysis involving all characters (accounts for 32.8 per cent of the total variance in all characters measured) and character $21-$ loadings on the first component of a Principal Components Analysis involving only flower size characters (accounts for 66.8 per cent of the total variance in the six characters)

\begin{tabular}{|c|c|c|c|c|}
\hline Character & Units & Description & $\begin{array}{c}20.1 \text { st PCA } \\
\text { Comp } 1\end{array}$ & $\begin{array}{c}21.2 \text { nd PCA } \\
\text { Comp } 1\end{array}$ \\
\hline 1. Flowering time & days & Time to flowering once in long days & 0.280 & \\
\hline 2. Flower width & $\mathrm{mm}$ & Figure 1a & 0.355 & 0.435 \\
\hline 3. Corolla length & $\mathrm{mm}$ & Figure $1 \mathrm{~b}$ & 0.347 & 0.425 \\
\hline 4. Pistil length & $\mathrm{mm}$ & Figure $1 \mathrm{c}$ & 0.342 & 0.440 \\
\hline 7. Stigma lobe length & $\mathrm{mm}$ & Figure 1f & 0.300 & 0.381 \\
\hline 8. Spot number & & Number of red spots on corolla & 0.107 & \\
\hline 9. Largest spot & $\mathrm{mm}$ & Width of largest spot & 0.247 & \\
\hline 10. Herkogamy & $\mathrm{mm}$ & Figure 1g & 0.154 & \\
\hline 11. Anther separation & $\mathrm{mm}$ & Figure $1 \mathrm{~h}$ & -0.032 & \\
\hline 12. Stigma exsertion & & Ratios of characters $5: 4$ & -0.115 & \\
\hline 16. Autofertility & & See text & 0.035 & \\
\hline 17. Seed yield & $\mathrm{mg}$ & See text & 0.127 & \\
\hline 18. Seed number & & See text & 0.161 & \\
\hline 19. Seed size & $\mathrm{mg}$ & See text & -0.152 & \\
\hline
\end{tabular}
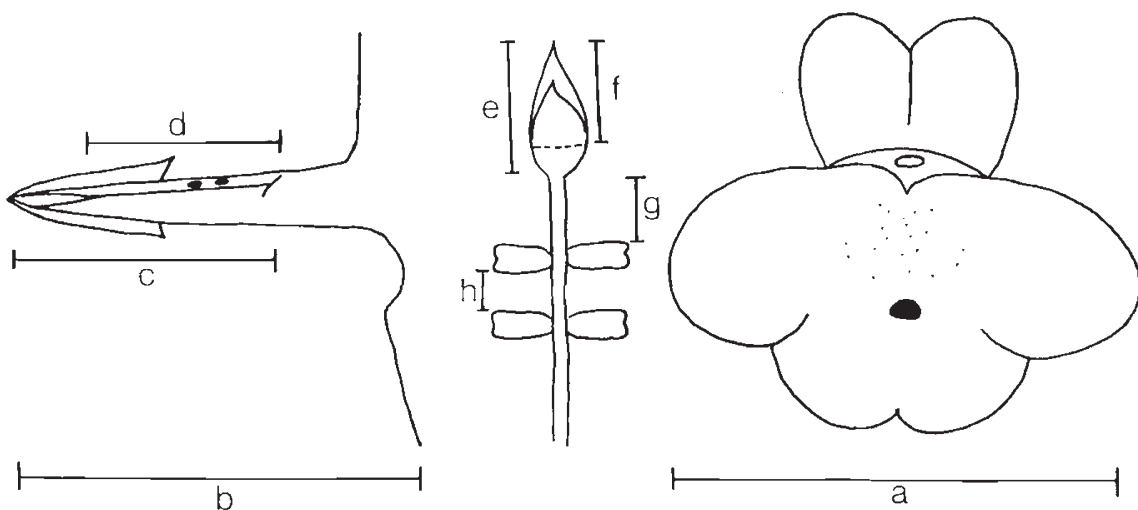

Fig. 1 Schematic diagram of $M$. guttatus flower showing the floral measurements made (Table 1). (a) Flower width, (b) corolla length, (c) pistil length, (d) style length, (e) stigma length, (f) stigma lobe length, (g) herkogamy, (h) anther separation.
Pollen viability and number were scored from an unopened flower bud that had been preserved in alcohol and acetic acid. The four anthers were dissected out and placed into vials containing $0.3 \mathrm{ml}$ $0.7 \mathrm{M}$ mannitol solution coloured with a little acetocarmine to stain the cytoplasm. The anthers were well macerated with a glass rod to release the pollen. After staining, a sample of grains was transferred to a haemocytometer slide for counting. Four independently drawn samples from each vial were counted and the numbers pooled. Typical samples contained 300-400 grains and were used to estimate the total number of grains per flower. Inviable pollen, having no cytoplasm, appears transparent after staining and contrasts strongly with the densely-staining viable grains. Separate counts were made of each category and viability calculated as a proportion of the total.

One flower was hand-pollinated with ample pollen to set full seed to score seed production. The corolla was removed and the stigma hand-pollinated with a mixture of pollen collected from five plants unrelated to the six parent plants used in the study but chosen from the original batch of plants from which the parents were derived. Intact anthers were collected from the pollen donors and allowed to dehisce their pollen in a glass vial. When all anthers had dehisced 
(3-5 h), the pollen was mixed thoroughly and applied to recipient stigmas. After approximately 3 weeks, the ripe capsules were harvested. The total yield of seed was weighed as well as a random sample of 50 seeds to estimate average seed size and extrapolated to estimate the numbers of seed produced.

The amount of autofertility was recorded as the proportion of fruits that set seed. All capsules were harvested from each plant from non-hand-pollinated flowers and classified according to fruit set into three categories: 0 , no seeds set; 1 , some seeds in the stylar end of the ovary only; 2 , seeds along all or most of the ovary. An index of autofertility was calculated as

$\frac{0.5 f_{1}+f_{2}}{f_{0}+f_{1}+f_{2}}$

where $f_{0}$ equals the frequency of capsules in category 0 etc. For the first block of plants, pollen and ovule production and flower size were remeasured 2 weeks after the first flowers appeared to see if plants that produced less pollen initially or selfed less were able to maintain ovule and seed production at a higher level than those that had invested heavily in pollen.

\section{Analyses}

All analyses used the family means for each cross type in each of the two blocks, i.e. $6 \times 6 \times 2=72$ data points and were performed using the statistical computer package MINITAB. In some cases, less than three replicates of each cross were scored because some plants either died or failed to develop proper flowers.

To determine the underlying genetic structure of the phenotypic variance observed in the data, in particular whether there was a significant additive genetic variance that could be worked on by selection, a full diallel analysis following Mather \& Jinks (1982) was performed. A PASCAL computer program written by one of us (M.R.M.) was used for this purpose. In all cases a Bartlett's test of homogeneity of variance among the individual block $\times$ main effect interactions showed no significant differences and so the pooled block interactions were used. Where the simple additivedominance and additive-environmental model is adequate, the $a$ term is equivalent to the additive genetic variance and the $b$ items the dominance effects. The $b_{1}$ term describes directional dominance, the $b_{2}$ term whether the degree of dominance differs between arrays and the $b_{3}$ the individual $\mathrm{F}_{1}$ contributions to the dominance. The $c$ and $d$ terms describe reciprocal differences between the maternal and paternal lines. An assumption of the analysis as presented by Mather \& Jinks (1982) is that the parents are derived from inbred lines and are therefore homozygous for all alleles. However, Dickinson \& Jinks (1956) have shown that as long as parents contribute an equal number of gametes to each family, then the analysis can be used without restriction to diallels involving heterozygous parents.

The total sum of squares was divided into additive genetic $\left(V_{\mathrm{a}}\right)$, genetic interaction $\left(V_{\mathrm{i}}\right)$, block (environmental) effects $\left(V_{\mathrm{b}}\right)$ and error $\left(V_{\mathrm{e}}\right)$ following the methods of Wearden (1965). Reciprocal and maternal effects were largely insignificant (see Results) so were ignored for this analysis. The individual contributions of $V_{\mathrm{a}}, V_{\mathrm{i}}, V_{\mathrm{b}}$ and $V_{\mathrm{e}}$ to the total of all four was evaluated and expressed as a proportion.

To discover whether each character was distributed independently of the others or if there were sets of correlated characters that could be reasonably condensed into principal components, a principal component analysis was performed on all the family means. For characters that are highly correlated, the principal components can be regarded as summary statistics and their inheritance investigated where they are both substantial (i.e. an eigenvalue greater than 1) and meaningful (Boag, 1983). In this case, only the first PC was important (see Results) and could be interpreted as a general size vector. The scores on the first PC are presented with the sign reversed so that large flowers had positive scores and small flowers negative scores. To investigate whether all the genetic variance detected in these correlated characters was due to the basic genetic system summarized by the first PC or whether there was additional genetic variation affecting the character studied independent of the first PC, an analysis of covariance was performed, taking out the effect of the correlation between the character studied and the first PC. The residual variation can still be partitioned into genetic and environmental effects and the significance of the genetic effects tested.

We are not aware that this technique has been used in this way before but believe that it is justified. A correlation between two characters can be caused by environmental correlation or genetic correlation or both. Suppose that two characters are only correlated because of environmental correlation. The summary statistic of these two characters should show rather small heritability but in the analysis of covariance it would be the error variance that would be reduced by the correlation with the PC. This should increase the significance of the genetic components. On the other hand, if the two characters were manifestations of the same genes, then the PC should show considerable heritability but the genetic effects will be reduced by this correlation in the ANCOVA. 
Following the methods of Falconer (1989), genetic correlations were estimated between ovary size, pollen and seed production and flower size (as determined by the first component of a second PCA which utilized flower size characters other than those directly related to pollen or ovule production as listed in Table 1).

\section{Results}

For all characters, a wide range of phenotypes was obtained in the $F_{1}$ generation (Table 2). The means of the selfs of the six parent genotypes differ considerably in all characters indicating the chosen parents covered a wide range of phenotypes. Below, the variance in each character is partitioned into components. The genetic variance includes the heritable component (the additive genetic variance), as well as dominance and parental effects. Block effects account for a further portion of the total variance and represent phenotypic plasticity. Finally, it may be possible to partition out variance due to a correlated response to another variable such as flower size. The remaining unaccounted variance is error and environmental effects not accounted for by block differences.

\section{Partitioning the variance: genes vs. environment}

The first principal component explained a modest proportion of the total variance in all characters considered together and was correlated most strongly with general flower size characters (Table 1). This indicates that those characters respond to overall changes in flower size. However, much variance remains that cannot be reduced to suites of correlated characters through PCA. The remaining principal components explained little variance and were disregarded.

Partitioning the wide range of phenotypes by analysis of variance reveals a highly significant additive genetic component for all characters except pollen number (Table 3). Characters that may be considered directly related to fitness, in particular, autofertility, pollen viability, ovary size and seed number, all show significant heritable variation.

Several characters show significant $b$ and $b_{1}$ terms indicating directional dominance. Flower size characters and pollen number and viability are reduced in the parent selfs compared with the $F_{1} s$, suggesting inbreeding depression through recessive genes (Table 2). Only two-thirds of the amount of pollen is produced by selfs compared with outcrosses and of this amount, more of it is inviable leading to a relative viable pollen production of selfs of just over 0.5 . Ovule and seed production are apparently less affected by inbreeding.

The pollen characters also have significant $b_{2}$ terms implying gene asymmetry. Seed size shows dominance effects specific to individual crosses as indicated by the $b_{3}$ term. There is very little evidence of reciprocal effects ( $c$ and $d$ terms) implying that cytoplasmic inheritance of, for example, the partial male sterility observed in some families, is unlikely.

During the experiment, plants in block 2 grew better than the plants in block 1 and many of the floral size characters showed large differences in means in the two blocks (Table 2). Flower and ovary size and seed fecundity were all larger in block 2 indicating that flower size and seed production are quite plastic and will respond to conditions that allow larger flowers. Pollen number was also higher in the second block but was apparently less affected than ovule production. Given the degree of correlated response between many of the characters, could it be that some characters are responding to variation in overall flower size and have no independent genetic basis? Indeed, analyses of covariance reveal significant associations between the PC1 score and many of the characters (Table 3). However, even when the general flower size is partitioned out by ANCOVA, for most characters, the significance of the various genetic components remains, although in many cases it is reduced.

We have thus identified several important independent components to the total variance of many of the characters. What then is the relative importance of additive genetic, genetic interactions including dominance and inbreeding effects, block effects and the remainder (error)? For many of the characters, additive genetic variance explains a large proportion of the total variance (Table 4). Flowering time, style length, spot number and size, the spatial arrangement of flowers (herkogamy, anther separation and stigma exsertion), pollen viability, autofertility and seed size all have between a quarter and a half of the variance accounted for by additive genetic variance indicating a strong potential for selection under these conditions. Some characters, in particular the characters related to flower size, are highly influenced by the environment (block effect) and are much less under genetic control. Others show a high error component possibly due to experimental error (e.g. variable seed set due to uneven pollination) or difficulties in accurate measurement (e.g. herkogamy, anther separation). Pollen production (quality and number) is highly dependent on genetic interactive effects, probably mainly inbreeding depression (Table 2).

\section{Autofertility}

Autofertility varied considerably among the families (Table 2). This variation has a strong additive genetic component but also apparently a lot of unexplained error (Table 4). There was no relationship with flower 


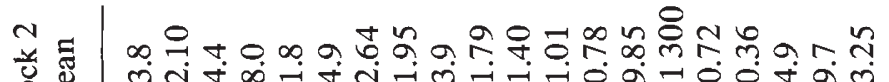

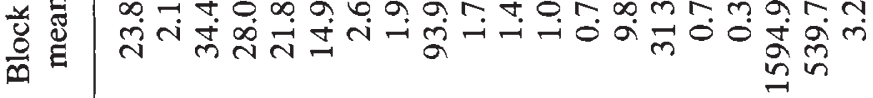

चี ซ

$\stackrel{\circ}{\mathscr{C}}$

角

= ก กิ 造造

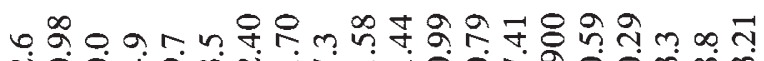
ते

onamogom:inmmn ํㅝ THM

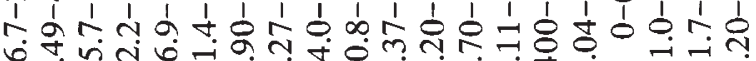

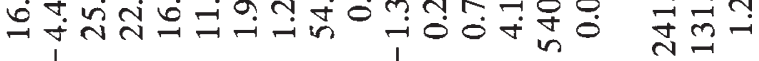

우의 तิ

ง

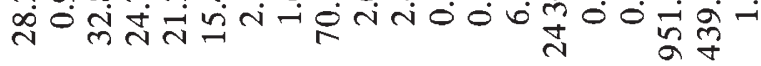

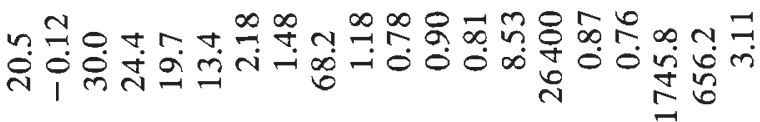

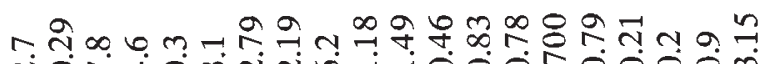
तั

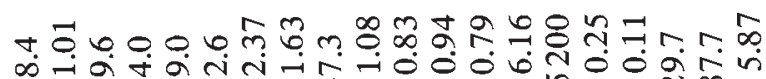
品

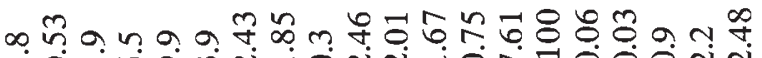
लें 


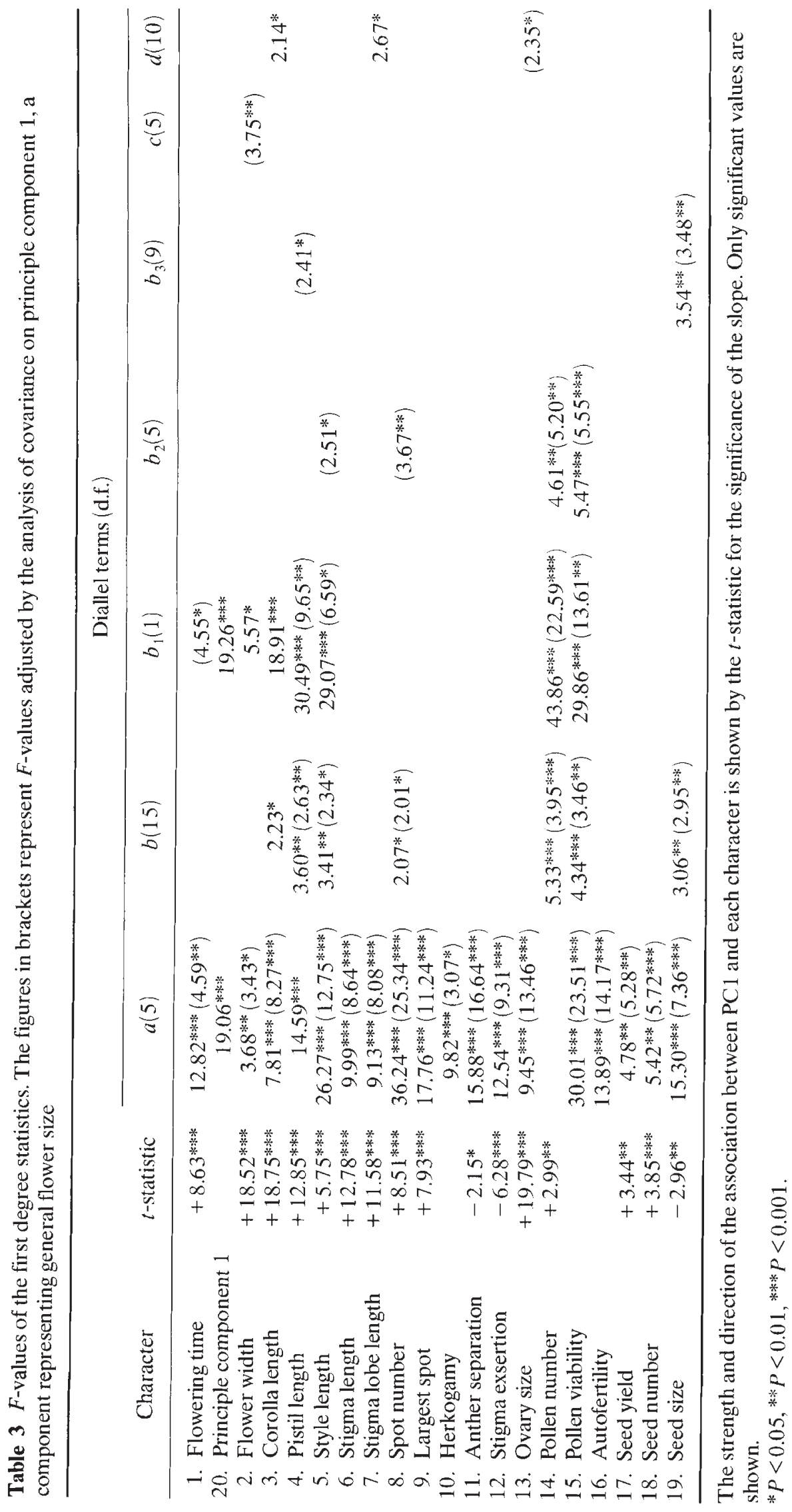


Table 4 Partitioning the total variance into components following Wearden (1965)

\begin{tabular}{lrrrr}
\hline Character & \multicolumn{1}{l}{$V_{\mathrm{a}}$} & \multicolumn{1}{l}{$V_{\mathrm{i}}$} & \multicolumn{1}{l}{$V_{\mathrm{b}}$} & \multicolumn{1}{c}{$V_{\mathrm{e}}$} \\
\hline 1. Flowering time & $\mathbf{0 . 2 7}$ & 0.04 & $\mathbf{0 . 4 1}$ & $\mathbf{0 . 2 8}$ \\
20. Principal component 1 & 0.10 & 0.02 & $\mathbf{0 . 8 2}$ & 0.07 \\
2. Flower width & 0.04 & -0.02 & $\mathbf{0 . 8 1}$ & 0.17 \\
3. Corolla length & 0.05 & 0.05 & $\mathbf{0 . 7 9}$ & 0.10 \\
4. Pistil length & 0.17 & 0.16 & $\mathbf{0 . 5 1}$ & 0.15 \\
5. Style length & $\mathbf{0 . 4 6}$ & 0.22 & 0.09 & 0.22 \\
6. Stigma length & 0.17 & -0.01 & $\mathbf{0 . 6 0}$ & 0.23 \\
7. Stigma lobe length & 0.14 & 0.07 & $\mathbf{0 . 5 7}$ & 0.21 \\
8. Spot number & $\mathbf{0 . 4 3}$ & 0.07 & $\mathbf{0 . 3 6}$ & 0.15 \\
9. Largest spot & $\mathbf{0 . 2 9}$ & 0.04 & $\mathbf{0 . 4 7}$ & 0.21 \\
10. Herkogamy & $\mathbf{0 . 4 1}$ & 0.00 & 0.02 & $\mathbf{0 . 5 6}$ \\
11. Anther separation & $\mathbf{0 . 5 4}$ & -0.01 & 0.03 & $\mathbf{0 . 4 4}$ \\
12. Stigma exsertion & $\mathbf{0 . 3 1}$ & 0.01 & $\mathbf{0 . 3 5}$ & $\mathbf{0 . 3 2}$ \\
13. Ovary size & 0.08 & 0.00 & $\mathbf{0 . 8 0}$ & 0.12 \\
14. Pollen number & 0.04 & $\mathbf{0 . 5 8}$ & 0.06 & $\mathbf{0 . 3 2}$ \\
15. Pollen viability & $\mathbf{0 . 4 9}$ & $\mathbf{0 . 2 9}$ & 0.02 & 0.20 \\
16. Autofertility & $\mathbf{0 . 4 6}$ & 0.06 & 0.05 & $\mathbf{0 . 4 3}$ \\
17. Seed yield & 0.17 & 0.17 & 0.13 & $\mathbf{0 . 5 4}$ \\
18. Seed number & 0.20 & 0.09 & 0.16 & $\mathbf{0 . 5 5}$ \\
19. Seed size & $\mathbf{0 . 3 7}$ & $\mathbf{0 . 2 6}$ & 0.06 & $\mathbf{0 . 3 1}$ \\
\hline
\end{tabular}

The relative contribution of the following components is expressed as a proportion of the total variance accounted by additive effects $\left(V_{\mathrm{a}}\right)$, genetic interactions $\left(V_{\mathrm{i}}\right)$, block effects $\left(V_{\mathrm{b}}\right)$ and error $\left(V_{\mathrm{e}}\right)$. Figures greater than 0.24 are highlighted in bold.

size as revealed by ANCOVA (Table 2) but a further analysis was performed to see if this variation could be explained by other factors, in particular the spatial separation between stigma and anthers, the separation between anthers and the quality of the pollen (to check for pollen limitation). An ANCOVA incorporating all these factors as covariates failed to explain a significant proportion of the variance in autofertility $\left(F_{[4,32]}=2.16\right.$ $0.10>P>0.05)$. The variation revealed in autofertility, although highly heritable, remains unexplained and the mechanism for the differences must be due to other unmeasured characteristics.

\section{Allocations to pollen, ovules and seeds}

The allocations to pollen and ovule and seeds varies considerably between families. Some of this variation is genetic while much is explained by the block effect. To see if some of the remaining variance was due to a trade-off between male and female reproduction, regressions were performed relating sex allocations and flower size of initial flowers and flowers produced after 2 weeks of the flowering period for that plant (Table 5). Ovary size was shown to be strongly correlated with flower size but showed no relationship with

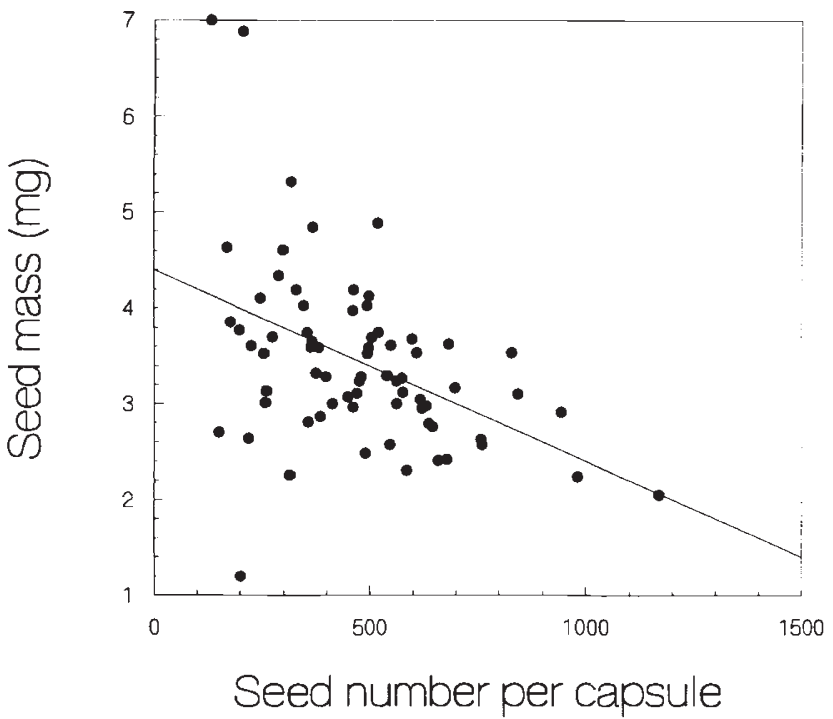

Fig. 2 The relationship between seed size and number. The line fitted is a least squares regression and has the following equation:

seed mass $=4.40-0.0020$ seed number.

The regression accounted for 19.4 per cent of the variance in seed size $(P=0.0001)$.

pollen production. Genetic correlations were also positive for both associations. Subsequent ovary size was apparently unrelated to flower size but was highly significantly and positively associated with pollen production. These results indicate that there is no trade-off between primary sex allocation. Seed mass was less easily predicted and only weak associations were found between the amount of seed produced from a handpollinated flower and any of the other measures of reproductive expenditure. A negative genetic correlation between flower size and seed production suggests a possible trade-off between floral advertising and seed filling. Seed size and number both show heritable variation irrespective of flower size variation (Table 3). There is also a significant negative relationship between seed number and seed size (Figure 2).

\section{Discussion}

Our study of floral characters of $M$. guttatus has revealed large additive genetic variances for many traits including autofertility, floral metrics and seed, ovule and pollen production. These results suggest that these characters should respond to directional selection and allow the evolution of novel morphologies and traits. This is in contrast to many published accounts of heritabilities of life-history traits of other wild populations where there is often very little additive variance 
Table 5 Multiple regressions predicting female allocation (ovary size and seed production) from male allocation (number of viable pollen produced), flower size ( 2 nd PCA, PC1) and the frequency of autofertility for flowers produced initially and those produced 2 weeks subsequently

Predictors

\begin{tabular}{lcccc} 
Parameter & Model & Pollen production & Flower size & Autofertility \\
\hline Ovary size & & & & \\
Initial & $F_{2,69}=54.6^{* * *}$ & $-1.92(0.496)$ & $+10.32^{* * * *}(0.375)$ & - \\
Subsequent & $F_{3,29}=10.24^{* * *}$ & $+4.48^{* * *}$ & +1.19 & -0.95 \\
Seed mass & $F_{2,69}=3.72^{*}$ & $+1.71(0.623)$ & $+1.43(-0.506)$ & - \\
Initial & $F_{3,29}=1.51$ & +1.78 & +0.03 & -1.21 \\
Subsequent & & &
\end{tabular}

The power of the model is presented in the first column and in subsequent columns, the direction and strength of predictive power as shown by the $t$-statistic for each predictor followed by the genetic correlation (in brackets).

(Dorn \& Mitchell-Olds, 1991). The components of variance presented here were measured in plants grown in a relatively uniform and favourable environment of two glasshouses. Native field conditions are obviously very different and frequently fluctuating so there may be a problem in extrapolating these results to the field (Service \& Rose, 1985). There is a considerable range of sizes of plants on Copperopolis mine depending on the availability of water where the plants are growing. Along the edge of streams where there is running water, plants are large and may have many hundreds of flowers (Macnair, personal observations). A few metres away from the stream course, however, the soil is very arid and dry and the plants much smaller, typically with two to three flowers open at one time (Martin, 1988). Indeed, even within the fairly narrow environmental range experienced in this study, plasticity was evident in many characters as shown by the high proportion of total phenotypic variance accounted for by block effects (Table 4). In particular, characters associated with overall flower size were particularly plastic (although many still showed some additive genetic variance) and so heritable variation in these characters may be of minor importance. However, many of the other characters were largely insensitive to differences between blocks and much of the variance in these characters appeared to have a genetic basis. It might have been expected that many of the metric characters of flowers will be tightly correlated with flower size to preserve floral structure with increases and decreases of flower size. An analysis of covariance shows that flower size indeed accounts for a highly significant part of the variance in many of these floral metrics as flower size is mainly controlled by environmental effects. However, most of these characters still show heritable variation of the residual indicating that there is room for selection to adjust the spatial arrangement of parts, for example, the degree to which the style reaches the top of the floral tube. This character has been shown to be important in determining the amount of pollen received and female reproductive success in hummingbird-pollinated Ipomopsis (Campbell, 1991; Campbell et al., 1991).

Thus we have identified some characters, namely those relating to flower and ovary size, that are broadly correlated and co-vary in response to environmental variation, while there are other characters such as spatial patterning within flowers, autofertility and pollen viability that vary independently of size and environmental effects. The variation in these latter characters appears to depend much more on genes and therefore, are, they potentially under selection in the field.

Fisher's fundamental theorem (Fisher, 1930) predicts that characters closely associated with fitness will have low additive genetic variance as directional selection will have exhausted any additive component. Assuming that at least some of the heritability found in the characters examined here is also expressed in the field, how is this variation maintained? Recently there has been much debate over how and why variation in characters closely associated with fitness is maintained. Some of these arguments may be relevant to the traits measured in our study and they will be discussed below.

As indicated above, the Copperopolis population spans a wide range of environmental conditions, particularly relating to water availability. Under such heterogeneous environments, genetic polymorphism can be maintained if there is a habitat-genotype interaction in selection differentials (Haldane \& Jayakar, 1963). In addition to this environmental heterogeneity, there is some evidence that there is a temporal heterogeneity for pollinator availability. The main pollinator of $M$. guttatus at this site appears to be the bumble bee, Bombus californicus (Martin, 1988). Plants begin to 
bloom at Copperopolis in April and in some years this apparently precedes the appearance of $B$. californicus at least for part of the season (Macnair, personal observation). This may be particularly true for plants that are off the main water channels as an early spring drought frequently curtails reproduction early in the season in these situations (Macnair, personal observation). At other times, however, the bees are abundant. Thus, plants may face an uncertainty of pollinator service. The ability to self-pollinate may be adaptive when pollinators are scarce and maladaptive when abundant if there is high inbreeding depression. Similar arguments have been advanced to account for the evolution of autogamous species within the $M$. guttatus complex (Kiang \& Hamrick, 1978; Dole, 1992). It will be argued below that these two causes of environmental and temporal heterogeneity lead to disruptive selection on many traits and hence oppose the erosion of additive variance through directional selection. Other traits may be selectively neutral or be under stabilizing selection and may therefore also not be expected to show this erosion.

The rate of autofertility of families ranged from 0 per cent fruit set to 84 per cent and this variation also has a strongly significant additive component. This self-pollination occurs late and may act as insurance if pollinators fail to pollinate flowers (Dole 1990, 1992). $M$. guttatus has been shown by allozyme studies to experience approximately a 50 per cent selfing rate (Ritland \& Ganders, 1987a; Ritland \& Ritland, 1989) although it is not known how much of this selfing occurs through geitonogamous pollen transfer by within-plant movements by pollinators. Dole (1992) identified stigma-anther contact during anthesis as the cause of self-pollination in some populations of $M$. guttatus, while in other populations, selfing occurred through corolla abscission dragging the anthers across the stigma. Our study has failed to find a strong causative relationship between flower morphology and autofertility, although there is a weak trend between selfing ability and herkogamy measured by the size of the gap between the upper anthers and the bottom of the lower stigmatic lobe. This study and other unpublished work by one us (A.D.) seems to confirm the importance of corolla abscission as the main means of autofertility in this population (see, however, Dudash \& Ritland, 1991) but we are unable to explain what causes the observed heritable variation in autofertility. Inbreeding depression appears to be high as shown by the poor pollen production of selfs and smaller flower size shown in this study and is confirmed by field studies which include inbreeding depression of over 50 per cent (Ritland \& Ganders, 1987b). At times when plants experience fluctuating levels of pollinator service, as indicated above, the ability to self may be at a selective advantage, while in times of pollinator abundance, a disadvantage through inbreeding depression. Such conditions could maintain the variance in autofertility observed.

Heritable variation in fitness characters can also be maintained if there is some form of 'antagonistic pleiotropy', i.e. a genetic 'trade-off' of two competing functions (Rose, 1982). It is widely expected that the production of ovules and of pollen in hermaphrodite plants involves such a trade-off and this assumption has been built into models of sex allocation (Charlesworth \& Charlesworth, 1981; Charnov, 1982; Ross \& Gregorius 1983; Lloyd, 1987). A plant that saves on the allocation to pollen may be expected to be better able to resource seeds and, depending on the shape of the gain curves for resource allocation, this may lead to frequency-dependent selection for separate sexes (Charnov, 1982; Ross \& Gregorius, 1983). Evidence of such a trade-off between functions has been found in several cases but not universally (review by Charlesworth \& Morgan, 1991). There is no evidence of such a trade-off operating in this population of M. guttatus. Pollen number variation is subject to gene interaction effects and shows inbreeding depression as evidenced by the wide difference in parental and $F_{1}$ means (Table 2). Pollen quality, however, shows highly significant additive genetic variation resulting in wide differences between families in the amount of viable pollen produced. It should be noted, however, that the parents used for the diallel were chosen on the basis of pollen viability so the genetic variance may be somewhat inflated over a random sample. Ovary size, which is highly correlated with ovule number, shows a relatively small but significant amount of heritable variation which remains even after flower size variation is partitioned out. Families are thus highly heterogeneous in phenotypic gender with large differences in pollen:ovule ratios. However, ovary size and seed production appear to vary largely independently of pollen production. The only significant association is a positive relationship between ovary size and viable pollen production in the batch of plants that was allowed to flower for 2 weeks. Genetic correlations between male and female allocation were also positive. Only flower size and seed mass showed a negative genetic correlation possibly suggesting a trade-off between advertising costs and seed filling, although it is not possible to test the statistical significance of the genetic correlation observed (Falconer, 1989). An independent study of plants from the same source but followed through the life-span of plants in the glasshouse also failed to find evidence for a trade-off between male and female allocations (Mossop et al., 1994). As in the present 
study, Mossop et al. also found a positive association between pollen and seed production.

Seed size and number both display heritable variation in this population. Seed size is frequently associated with seedling quality (reviewed by Haig \& Westoby, 1988) and in M. guttatus, smaller seeds germinate and grow more slowly than large seeds (M. R. M., unpublished data). Seed size is frequently considered an invariant property in many populations (Harper et al., 1970). The average seed size presented here more than doubles between the largest and smallest seeds. There is evidence of a trade-off between seed number and size in our data. Smaller more numerous seeds may be an advantage in ensuring wide dispersal but under conditions of strong localized competition, fewer larger seeds may be advantageous. Again, depending on seasonal conditions and habitat type, one or other strategy may be favoured which may maintain heritable variation in seed size-number strategy.

It is postulated that the heritable variation observed in our data on floral traits of $M$. guttatus may be maintained by disruptive and/or stabilizing selection. Many of the results and ideas presented need confirmation in the field and, following the lead of Campbell (Campbell, 1991; Campbell et al., 1991), studies of selection differentials for both maternal and paternal fitness over periods of environmental fluctuation would be enlightening.

\section{Acknowledgements}

This study was supported by NERC research grant GR3/7182, and A.D. was in receipt of a SERC studentship. James Cresswell and two anonymous referees commented on an earlier draft, Karen Breadmore helped score some of the characters and Phil Goodson assisted with plant propagation; the assistance of all is gratefully acknowledged.

\section{References}

ARTHUR, A. E., GALE, J. S. AND LAWRENCE, M. J. 1973. Variation in wild populations of Papaver dubium. VIl. Germination time. Heredity, 30, 189-197.

BAKER, H. G. 1983. An outline of the history of anthecology, or pollination biology. In: Real, L. (ed.) Pollination Biology, pp. 7-28. Academic Press, Orlando.

BIERE, A. 1991 a. Parental effects in Lychnis flos-cuculi. I. Seed size, germination and seedling performance in a controlled environment. J. Evol. Biol., 4, 447-465.

BIERE, A. 1991b. Parental effects in Lychnis flos-cuculi. II. Selection on time of emergence and seedling performance in the field. J. Evol. Biol., 4, 467-486.
BOAG, P. T. 1983. The heritability of external morphology in Darwin's ground finches (Geospiza) on Isla Daphne Major, Galapagos. Evolution, 37, 877-894.

CAMPBELL, D. R. 1991. Effects of floral traits on sequential components of fitness in Ipomopsis aggregata. Am. Nat., 137, 713-737.

CAMPBEll, D. R., WASER, N. M., PRICE, M. V., LYNCH, E. A. AND MITCHELL, R. J. 1991. Components of phenotypic selection - pollen export and flower corolla width in Ipomopsis aggregata. Evolution, 45, 1458-1467.

CHARLESWORTH, D. AND CHARLESWORTH, B. 1981. Allocations of resources to male and female functions in hermaphrodites. Biol. J. Linn. Soc., 15, 57-74.

CHARLESWORTH, D. AND MORGAN, M. T. 1991. Allocation of resources to sex functions in flowering plants. Phil. Trans. R. Soc. Lond. B, 332, 91-102.

charnov, E, 1982. The Theory of Sex Allocation. Princeton University Press, Princeton.

DARWIN, C. 1862. On the Various Contrivances by which Orchids Are Fertilised by Insects. Murray, London.

DICKINSON, A, G. AND JINKS, J. L. 1956. A generalised analysis of diallel crosses. Genetics, 41, 65-78.

DOLE, J. A. 1990. Role of corolla abscission in delayed selfpollination of Mimulus guttatus (Scrophulariaceae). Am. .J. Bot., 77, 1505-1507.

DOLE, J. A. 1992. Reproductive assurance mechanisms in three taxa of the Mimulus guttatus complex (Scrophulariaceae). Am. J. Bot., 79, 650-659.

DORN, L. A. AND MITCHELL-OLDS, T. 1991. Genetics of Brassica campestris. I. Genetic constraints on evolution of lifehistory characters. Evolution, 45, 371-379.

DUDASH, M. R. AND RITLAND, K. 1991. Multiple paternity and self-fertilization in relation to floral age in Mimulus guttatus (Scrophulariaceae). Am. J. Bot., 78, 1746-1753.

FALCONER, D. S. 1989. Introduction to Quantitative Genetics, 3rd edn. Longman, London.

FISHER, R. A. 1930. The Genetical Theory of Natural Selection. Clarendon Press, Oxford.

GALEN, C. 1989. Measuring pollinator-mediated selection on morphometric floral traits: bumblebees and the Alpine Sky Pilot, Polemonium viscosum. Evolution, 43, $882-890$

HAIG, D. AND WESTOBY, M. 1988. Inclusive fitness, seed resources and maternal care. In: Lovett Doust, J. and Lovett Doust, L. (eds) Plant Reproductive Ecology, pp. 60-79. Oxford University Press, New York.

HAldane, J. B. S. AND JayakaR, S. D. 1963. Polymorphism due to selection of varying direction. J. Genet., 58, 237-242.

HARPER, J. L., LOVELL, P. H. AND MOORE, K. G. 1970. The shapes and sizes of seeds. Ann. Rev. Ecol. Syst., 1, 327-356.

KIANG, Y. T. AND HAMRICK, J. L. 1978. Reproductive isolation in the Mimulus guttatus-M. nasutus complex. Am. Midl. Nat., 100, 269-276.

LANDE, R. 1976. The maintenance of genetic variability by mutation in a polygenic character with linked loci. Genet. Res., 26, 221-235.

LLOYD, D. G. 1987. Allocations to pollen, seeds and pollination mechanisms in self-fertilizing plants. Funct. Ecol., 1, 83-89. 
MACNAIR, M. R. AND CUMBES, Q. J. 1989. The genetic architecture of interspecific variation in Mimulus. Genetics, 122, 211-222.

MARTIN, B. E. 1988. Floral fragrance and pollination in the yellow monkey flower Mimulus guttatus Fischer ex D.C. (Scrophulariacae). Ph.D. Thesis, University of Exeter.

MATHER, K. AND JinKS, J. L. 1982. Biometrical Genetics, 3rd edn. Chapman and Hall, London.

MAZER, S. J. 1987. The quantitative genetics of life history and fitness components in Raphanus rhaphanistrum $\mathrm{L}$. (Brassicaceae): ecological and evolutionary consequences of seed-weight variation. Am. Nat., 130, 891-914.

MITCHELL-OLDS, T. 1986. Quantitative genetics of survival and growth in Impatiens capensis, Evolution, 40, 107-116.

MITCHELL-OLDS, T. AND RUTLEDGE, J. J. 1986. Quantitative genetics in natural plant populations: a review of the theory. Am. Nat., 127, 379-402.

MOSSOP, R., MACNAIR, M. R. AND ROBERTSON, A. w. 1994. Within population variation in sexual resource allocation in Mimulus guttatus. Funct. Ecol, in press.

RICK, C. M., FORBES, J. F. AND HOLLE, M. 1977. Genetic variation in Lycopersicon pimpinellifolium: evidence of evolutionary change in mating systems. Plant Syst. Evol., 127, 139-170.

RITLAND, C. AND RITLAND, K. 1989. Variation of sex allocation among eight taxa of the Mimulus guttatus species complex (Scrophulariaceae). Am. J. Bot., 76, 1731-1739.

RITLAND, K. 1989. Correlated matings in the partial selfer $\mathrm{Mi}^{-}$ mulus guttatus. Evolution, 43, 848-859.

RITLAND, K. AND GANDERS, F. R. 1987a. Covariation of selfing rates with parental gene fixation indexes within populations of Mimulus guttatus. Evolution, 41, 760-771.
RITLAND, K. AND GANDERS, F. R. 1987b. Crossability of Mimulus guttatus in relation to components of gene fixation. Evolution, 41, 772-786.

ROBERTSON, A. W. AND LLOYD, D. G. 1991. Herkogamy, dichogamy and self-pollination in six species of Myosotis (Boraginaceae). Evol. Trends Plants, 5, 53-63.

RoSE, M. R. 1982. Antagonistic pleiotropy, dominance and genetic variation. Heredity, 48, 63-78.

ROSS, M. D. AND GREGORIUS, H. R. 1983. Outcrossing and sex function in hermaphrodites: a resource-allocation model. Am. Nat., 121, 204-222.

SCHWAEGERLE, K. E. AND LEVIN, D. A. 1991. Quantitative genetics of fitness traits in a wild population of Phlox. Evolution, 45, 169-177.

SEARCY, K. B. AND MACNAIR, M. R. 1990. Differential seed production in Mimulus guttatus in response to increasing concentrations of copper in the pistil by pollen from copper tolerant and sensitive sources. Evolution, 44, 1424-1435.

SERVICE, P. M. AND ROSE, M. R. 1985. Genetic covariance among life-history components: the effect of novel environments. Evolution, 39, 943-945.

STANTON, M., YOUNG, H. J., ELLSTRAND, N. C. AND CLEGG, J. M. 1991. Consequences of floral variation for male and female reproduction in experimental populations of wild radish, Raphanus sativus L. Evolution, 45, 268-280.

VASEK, F. C. 1965. Outcrossing in natural populations. II. Clarkia unguiculata. Evolution, 19, 152-156.

WEARDEN, s. 1965. Alternative analysis of the diallel cross. Heredity, 20, 669-680. 